This paper was retracted on November 19, 2021.

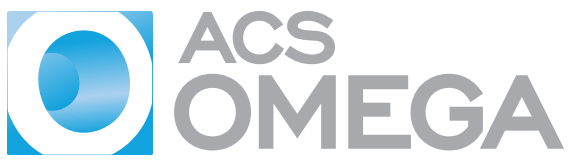

쇼요 (1) $\odot$

\title{
Effect of Modified Zeolite $\beta$ in the Hydrogenation of Anisole and Acetophenone Reaction
}

\author{
V. L. Mangesh, Tamizhdurai Perumal,* Santhana Krishnan Perumal, Kumaran Rajendran, \\ Narayanan Subramanian, Mani Govindasamy, Ayman A. Ghfar,* Murefah mana AL-Anazy, \\ and Mohamed Ouladsmane
}

Cite This: https://doi.org/10.1021/acsomega.1c03566

Read Online

Wlll Metrics \& More

回国 Article Recommendations

SI Supporting Information

ABSTRACT: In this work, the hydrogenation of the anisole and acetophenone reaction over $\beta$-zeolite (BEA) is reported. The parent zeolite obtained from a commercial source was modified by various treatments, such as dealumination, desilication, and ion exchange, to increase its activity in the acylation reaction. In the present study, the $\mathrm{SiO}_{2} / \mathrm{Al}_{2} \mathrm{O}_{3}$ ratio $(\mathrm{SAR}=25)$ of the parent $\mathrm{BEA}$ was altered by dealumination with $\mathrm{HNO}_{3}$ (to SAR, 58, 88, and 170) and by desilication with tetrapropylammonium hydroxide. X-ray diffraction results showed that the BEA structure was maintained after various treatments. All of the catalysts were tested in the hydrogenation of the anisole and acetophenone reaction. When the reaction was carried out using 0.5 wt $\% \mathrm{Pd} / \mathrm{BEA}(58)$ at $155^{\circ} \mathrm{C}$ and 25 bar $\mathrm{H}_{2}$ pressure, acylation products were obtained. These studies point out that it is not possible to carry out both acylation of anisole and hydrogenation of ketone in a single pot and ketone needs to be separated from anisole prior to its hydrogenation. Summing up, the studies reveal that BEA modified by mild dealumination/desilication is suitable for the acylation of anisole with long-chain acids. Also, acylation over BEA produces mainly the p-acylated product (ketone), which is often the desired product. Pd/BEA is a good catalyst for the hydrogenation of ketone to alcohol (another desired product) or the alkyl aromatic hydrocarbon.

\section{INTRODUCTION}

Hydrogenation of anisole and acetophenone compounds has been utilized to produce aromatic ketones that find numerous applications in the manufacture of fine chemicals, fragrances, and pharmaceuticals. Current industrial acylation processes mostly use hazardous Lewis acids (e.g., $\mathrm{AlCl}_{3}, \mathrm{BF}_{3}$, and $\mathrm{FeCl}_{3}$ ) as catalysts and acyl halides as acylating agents. ${ }^{1-3}$ The major drawback in the conventional manner of making aromatic ketones is the need to use stoichiometric (or more) amounts of the Lewis acid, their separation, disposal of the acids, and the corrosive nature of the acyl halides and the acids. ${ }^{4}$ Therefore, it is greatly beneficial to carry out the reactions using carboxylic acids or carboxylic acid anhydrides as raw materials instead of acyl halides and nontoxic and easily separable solid acids as catalysts. ${ }^{5}$ Typical solid acid catalysts that can be used in acylation reactions are sulfated zirconia, Nafion-H, Nafion/ silica, pillared clays, rare earth exchanged pillared clays, Keggin-type heteropolyacids, and medium- and large-pore zeolites. $^{6-8}$

Botella et al. studied the use of $\beta$-zeolite for the synthesis of 4-methylacetophenone by acylation of toluene with acetic anhydride and obtained almost $95 \%$ of the acylation product selectively. ${ }^{9}$ They found that the inhibition step was desorption of the ketone, which was reduced using an excess amount of toluene as it helped in desorbing the ketone. ${ }^{10}$ The reaction was studied in the temperature range of $140-250{ }^{\circ} \mathrm{C}$. Vidhya et al. studied the acylation of anisole by acetic anhydride over a porous solid acid (Nafion SAC-13) and a heteropolyacid (HPA) to yield $p$-methoxyacetophenone (PMOAP); they obtained more than 95\% selective product with 45-50\% conversion of anhydride. Reaction conditions applied were 120 bar pressure, temperature $70{ }^{\circ} \mathrm{C}$, anisole/anhydride ratio $5: 1$, and space velocity of $1.6 \mathrm{~g}_{\text {acetic anhydride }} \mathrm{g}_{\text {cat }}{ }^{-1} \mathrm{~h}^{-1}$. However, both of these catalysts got deactivated in the liquid-phase operation within $24 \mathrm{~h}$, and the reason for the deactivation proposed for HPA was leaching of the Keggin ion, while for SAC-13, it was the adsorption of PMOAP in the micropores of the Nafion catalyst. SAC-13 was treated with boiling $\mathrm{HNO}_{3}$ solution to restore its complete activity. ${ }^{11,12}$

For more than 200 years, mineralogists have researched zeolites, which are microporous crystalline aluminosilicates. They are made up of molecular channels and cavities with

Received: July 7, 2021

Accepted: September 15, 2021 


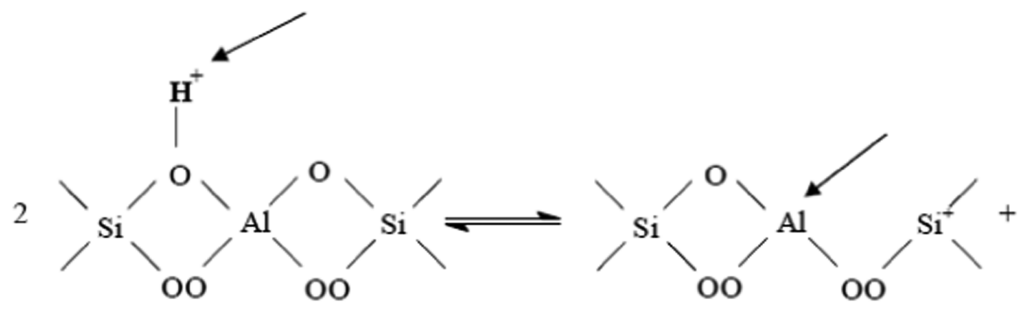

Brønsted acid sites

\section{Lewis acid sites}

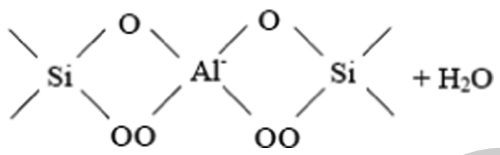

Figure 1. Brønsted and Lewis acid sites in the zeolite framework.

diameters ranging from 3 to $10 \AA$. The following is the general formula for a hydrated zeolite's composition

$$
\mathrm{M}_{x / n}\left[\left(\mathrm{AlO}_{2}\right)_{x}\left(\mathrm{SiO}_{2}\right)_{y}\right]_{z} \mathrm{H}_{2} \mathrm{O}
$$

where $M$ is an extraframework cation that balances the anionic charge of the framework, $n$ is the valency of $\mathrm{M}, x$ and $y$ represent the total amount of aluminate and silicate tetrahedra per unit cell, respectively, and $z$ is the number of water molecules per unit cell. Alkali metals, such as $\mathrm{Na}^{+}$and $\mathrm{K}^{+}$, alkaline earth metals, such as $\mathrm{Ca}^{2+}$ and $\mathrm{Ba}^{2+}$, and other cations, such as $\mathrm{NH}^{4+}$ and $\mathrm{H}^{+}$, are examples of common cations. ${ }^{13,14}$ Stilbite is a natural zeolite that was reported in 1756 by Alex Fredrich Cronstedt, a mineralogist from Sweden. The material was termed as "zeolite", where the Greek word "zeo" means boiling and the word "lithos" means stones because when fused into the blow-pipe, it swells and generates steam. ${ }^{15}$ Many natural zeolites, such as mordenite, clinoptilolite, natrolite, chabazite, heulandite, faujasites, and others, have been reported after that. Various synthetic zeolites have also been synthesized and reported. ${ }^{16}$

Because of the high demand for zeolites in commercial applications, they are synthesized in huge industrial numbers. More than 150 different zeolites have been produced. ${ }^{17}$ The Union Carbide Corporation United States had first developed synthetic zeolites in the 1950 s. Zeolites such as zeolite A, X, Y, mordenite, and ZSM-5 have all been commercially produced. Zeolite $\mathrm{Y}$ and zeolite $\mathrm{X}$ have found many catalytic applications in petroleum and petrochemical industries. ${ }^{18,19}$ The sodium type A zeolite, often known as $\mathrm{Na}-\mathrm{A}$, has a mean pore diameter of $4-6 \mu \mathrm{m}$ and is particularly well suited for the exchange of calcium ions in solution. As a result, it is used in the production of detergents. $^{20}$

Most zeolites are colorless crystalline powders that have alkali and alkaline earth metal cations. ${ }^{21}$ The presence of transition-metal impurities or the modification of zeolites by ion exchange with these elements may result in the appearance of color in zeolites. ${ }^{22}$ A typical main particle size ranges between 0.1 and $15 \mu \mathrm{m}$ in diameter. Single crystals often combine to create larger aggregates. When heated, hydrated zeolites expel water into the environment. By calcining zeolites at $400-500{ }^{\circ} \mathrm{C}$, it is possible to fully dehydrate them without causing significant structural changes. ${ }^{23}$ Zeolites have a low density, ranging between 1.9 and $2.3 \mathrm{~g} / \mathrm{cm}^{3}$, which makes them useful in a wide range of applications. Increased density as a result of cation exchange with heavy ions is seen in certain barium zeolites, which have densities as high as $2.8 \mathrm{~g} / \mathrm{cm}^{3}$. $^{24}$ Density depends on the zeolite structure's openness and cation content. The framework's thermal stability increases with the $\mathrm{SiO}_{2} / \mathrm{Al}_{2} \mathrm{O}_{3}$ ratio. The crystalline decomposition temperature of low-silica zeolites $\left(\mathrm{SiO}_{2} / \mathrm{Al}_{2} \mathrm{O}_{3}<5\right)$ is located between 700 and $1300{ }^{\circ} \mathrm{C}$, whereas in high-silica zeolites, the crystalline decomposition temperature is much higher. Zeolites exhibit distinct acid/base stability depending on the $\mathrm{SiO}_{2} / \mathrm{Al}_{2} \mathrm{O}_{3}$ framework ratio. Under acidic conditions, low-silica zeolites are unstable; however, high-silica zeolites are stable in the presence of strong mineral acids. In the opposite case, zeolites with a high percentage of silica are not stable in a basic solution, whereas zeolites with a lower percentage of silica have improved stability. ${ }^{25}$

The aluminum in zeolite makes it hydrophilic. The capacity of these materials to interact with hydrophobic organic molecules or exclude hydrophilic molecules, such as water, increases with increasing silica concentration and decreases with aluminum content. Hydrophilic-to-hydrophobic transition occurs when $\mathrm{SiO}_{2} / \mathrm{Al}_{2} \mathrm{O}_{3}=20$. The chemical reactivity of zeolites depends on whether they are hydrophilic or hydrophobic. $^{26}$ The ion-exchange capability of zeolite was discovered more than a century ago. Most zeolites do not suffer from significant dimensional changes during ion exchange due to their three-dimensional framework structure. The selective removal of radioactive ions from radioactive waste products is one use for naturally occurring zeolite minerals such as clinoptilolite. The type of the cationic species, cation size (both anhydrous and hydrated), cation charge, cation concentration in solution, and the structural features of the specific zeolite all influence the cation-exchange behavior of zeolites. $^{27}$ Zeolite has the ability to function as a molecular sieve due to the existence of variations in both form and size among the molecules to be isolated. Molecules of inappropriate shape or size may be completely rejected, while guest species with the appropriate shape and size can easily enter.

The strength of the acid sites determines zeolites' catalytic activity. ${ }^{28-30}$ In general, the greater the related Brønsted acidity, the lower the aluminum concentration of a zeolite or the higher the $\mathrm{Si} / \mathrm{Al}$ ratio. Several characterization methods have been developed to determine the acid sites and the relationship between the catalytic behavior of zeolites and their acidity in a qualitative and quantitative manner. In the present work, we have prepared BEA with different SAR by 
dealumination with $\mathrm{HNO}_{3}$ and investigated the hydrogenation of anisole and acetophenone (Figure 1).

\section{RESULTS AND DISCUSSION}

\subsection{Physicochemical Characterization of BEA Sam-} ples. The parent $\beta$-zeolite (CP814E, Zeolyst International) and its various modifications were characterized by a number of methods, such as XRF analysis for determining the $\mathrm{SiO}_{2} /$ $\mathrm{Al}_{2} \mathrm{O}_{3}$ ratio, $\mathrm{X}$-ray diffraction (XRD), $\mathrm{N}_{2}$ adsorptiondesorption isotherms for textural characterization, and TPD of $\mathrm{NH}_{3}$ for acidity measurement. The results of these characterization studies are presented in this section.

2.2. Characterization of Catalysts. The $\mathrm{NaY}(5.1)$ was used as a commercial sample (CBV100, Zeolyst International) with a total surface area of $735 \mathrm{~m}^{2} / \mathrm{g}$ and an external surface area of $34 \mathrm{~m}^{2} / \mathrm{g}$. The characterization of $\operatorname{BEA}(58)$ has already been described. XRD patterns of the metal-loaded zeolites were recorded to check if metal loading had any effect on the structural integrity of the zeolites. The XRD patterns of the parent zeolites and the metal-loaded samples were similar, and the metal-loading procedure had no effect on the structural integrity of the zeolites.

2.3. Compositional Analysis of Samples. As the acylation reaction is an acid-catalyzed reaction, it was decided to study the effects of altering the $\mathrm{Al}$ content $\left(\mathrm{SiO}_{2} / \mathrm{Al}_{2} \mathrm{O}_{3}\right.$ ratio) of the parent zeolite on its activity. This was carried out by (i) dealumination with $\mathrm{HNO}_{3}$ (to decrease the $\mathrm{Al}$ content and increase the $\mathrm{SiO}_{2} / \mathrm{Al}_{2} \mathrm{O}_{3}$ ratio) and (ii) desilication with tetrapropylammonium hydroxide $(\mathrm{TPAOH}$ ) (to increase the $\mathrm{Al}$ content and decrease the $\mathrm{SiO}_{2} / \mathrm{Al}_{2} \mathrm{O}_{3}$ ratio). The $\mathrm{SiO}_{2} /$ $\mathrm{Al}_{2} \mathrm{O}_{3}$ ratios of the zeolite after the dealumination and desilication treatments obtained from XRF analysis are presented in Table 1 . It is noticed that increasing the

Table 1. Compositional Analysis by XRF Spectroscopy

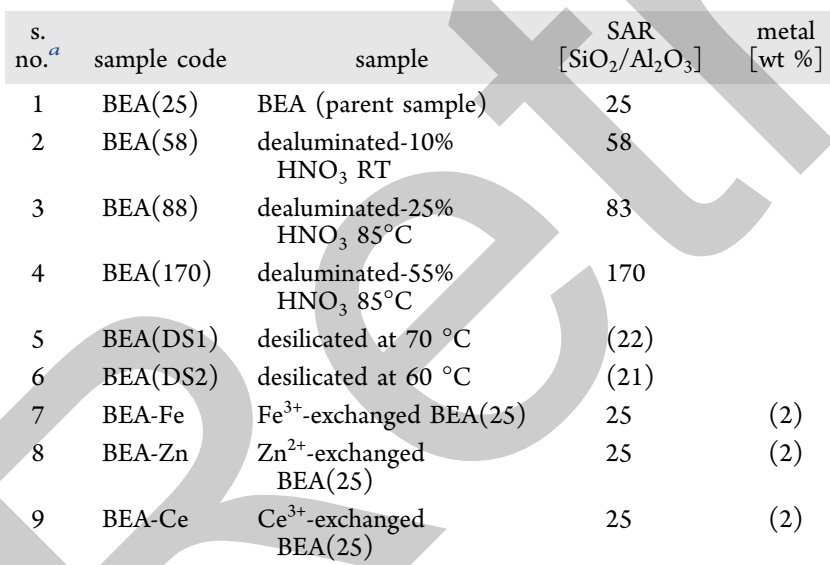

${ }^{a}$ Values in parentheses are estimated values based on an earlier work and metal content of solutions used for ion exchanging.

temperature of dealumination or increasing the acid $\left(\mathrm{HNO}_{3}\right)$ increases the dealumination, with nearly $85 \%$ of all of the $\mathrm{Al}$ being removed from the parent sample after treatment \#4. Similarly, increasing the temperature of the alkali (TPAOH) treatment increases the desilication.

2.4. X-ray Diffraction studies. The powder XRD patterns of the modified BEA samples are presented and discussed in this section. Figure $2 \mathrm{a}$ presents the XRD patterns of dealuminated samples calcined at $450{ }^{\circ} \mathrm{C}$. The XRD patterns of the samples did exhibit modest modifications, such as a little shift of the $d_{302}$ line toward higher $2 \theta$ values (Table 2) in comparison to the parent zeolite $\operatorname{BEA}(25)$ and some loss of peak intensity. The change in the $d_{302}$ line toward higher $2 \theta$ values is due to the absence of $\mathrm{Al}^{3+}$ ions in the framework and the resulting reduction in unit cell dimensions. The decrease in line intensity is due to the partial breakdown of the zeolite lattice (crystallinity loss) upon removal of the $\mathrm{Al}$ ions in the framework. $^{34}$

The crystallinity loss of the samples was calculated by evaluating the intensity of the most intense peak $\left(d_{302}\right)$ of the dealuminated sample to that of $\operatorname{BEA}(25)$ on the assumption that the parent zeolite had $100 \%$ crystallinity. Table 2 shows the relative crystallinities of the dealuminated samples. It is noticed that increasing the dealumination increases the crystallinity loss, and severe dealumination $\left(55 \% \mathrm{HNO}_{3}\right.$ at $85^{\circ} \mathrm{C}$; SAR $\left.=170\right)$ causes severe $(50 \%)$ loss in crystallinity. ${ }^{34}$ The average crystallite sizes of Parent $\operatorname{BEA}(25), \operatorname{BEA}(58)$, $\operatorname{BEA}(88)$, and $\operatorname{BEA}(170)$ are $45,42,39$, and $31 \mathrm{~nm}$, respectively.

The XRD patterns of two BEA samples desilicated with $\mathrm{TPAOH}$ are presented in Figure $2 \mathrm{~b}$. The patterns do not reveal significant changes in peak intensities or peak positions. This is due to the mild nature of the desilication process and the relatively small amounts of $\mathrm{Si}$ removed from the framework. The average crystallite sizes of BEA(DS1) and BEA(DS2) are 43 and $40 \mathrm{~nm}$, respectively. The XRD patterns of three BEA samples ion-exchanged with metals $\left(\mathrm{Fe}^{3+}, \mathrm{Zn}^{2+}, \mathrm{Ce}^{3+}\right)$ are displayed in Figure 2c. The average crystallite sizes of BEA-Fe, BEA-Zn, and BEA-Ce are 39, 37, and $41 \mathrm{~nm}$, respectively.

$\mathrm{Fe}^{3+}, \mathrm{Zn}^{2+}$, and $\mathrm{Ce}^{3+}$ ions were loaded in the BEA samples by the ion-exchange procedure. The amount of metal ions used during ion-exchange was expected to lead to a loading level of about 2 wt $\%$ of the metal. The exact quantity of the metal could not be estimated accurately. The XRD patterns of the metal-ion-loaded BEA samples are presented in Figure $2 \mathrm{~d}$. The XRD patterns do not reveal any additional peaks attributed to metal oxides presumably due to the small loading and their presence as ions in exchange positions in the zeolite. However, the intensities of the peaks are slightly decreased on loading of the metal ions. This is generally observed when large metal ions are loaded in zeolites. ${ }^{35}$

2.5. Surface Areas and Pore Volumes by $\mathrm{N}_{2}$ Sorption Analysis. Nitrogen adsorption isotherms of the different BEA samples were obtained at liq. $\mathrm{N}_{2}$ temperature to calculate surface areas and pore volumes. The adsorption isotherms of the different samples were typically of type-IVA with a type-I feature at lower $p / p_{0}$ values suggesting the presence of both micro- and mesopores. A typical adsorption-desorption isotherm of the parent BEA is presented in Figure $3 .^{36}$

The isotherms were analyzed using the BET and t-plot methods shown in Figure $3 \mathrm{~A}-\mathrm{C}$. The results of the analyses are shown in Table 3. Despite the fact that the BET equation is not precisely relevant for microporous zeolites, it is currently being utilized in our research for the sake of comparability and because a significant proportion of mesoporous area is present in the samples, which makes it more convenient to use. A quick calculation shows that the exterior surface of the parent zeolite, probably due to the tiny zeolite crystallites and mesoporous material present in the zeolite crystallites and amorphous material present in the samples, accounts for significant portions of the surface area. $S_{\mathrm{BET}}$ decreases on dealumination, while it increases slightly on desilication. Interestingly, $S_{\text {ext }}$ 

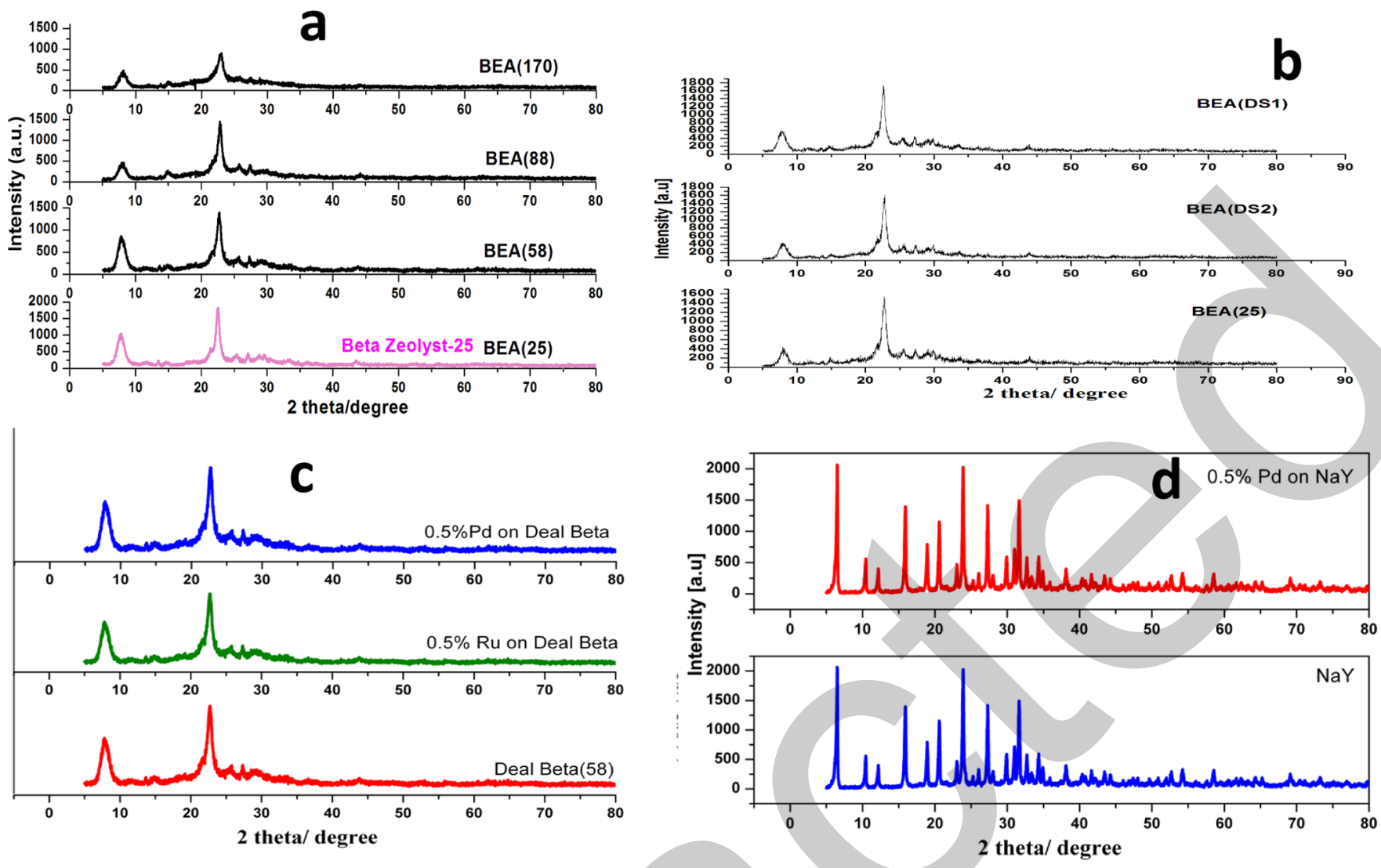

Figure 2. XRD patterns of (a) dealuminated samples and the parent BEA and (b) desilicated samples and the parent BEA. (c) X-ray diffraction patterns for metal-loaded BEA(58). (d) X-ray diffraction patterns for metal-loaded $\mathrm{NaY}(5.1)$.

Table 2. Relative Crystallinities of the Parent and Dealuminated Samples

\begin{tabular}{cccc} 
sample code & $\% \mathrm{Al}$ ions removed & $d_{302}(\mathrm{deg}, 2 \theta)$ & relative crystallinity (\%) \\
SAR $(25)$ & 0 & 22.5 & 100 \\
$\operatorname{SAR}(58)$ & 57 & 22.7 & 90.6 \\
$\operatorname{SAR}(88)$ & 72 & 22.9 & 84.3 \\
$\operatorname{SAR}(170)$ & 85 & 23.0 & 50 \\
\hline
\end{tabular}

decreases after both treatments and increases with mild dealumination (to SAR $=58$ ) and decreases with strong dealumination treatments; $S_{\text {micro }}$ increases on desilication. The decrease in $S_{\text {ext }}$ is essentially due to the dissolution of the amorphous material. The increase in $S_{\text {micro }}$ on mild dealumination and desilication (essentially, mild treatments) is due to the removal of the debris ( $\mathrm{Si}$ and $\mathrm{Al}$ species) from the pore system, making the pores more accessible to $\mathrm{N}_{2}$ molecules. This argument is supported by the slight increase in the micropore volume noticed on mild dealumination and desilication.

Interestingly, the total pore volume increases with both treatments; the rise seems to be mostly attributable to an increase in the mesopore volume. The average diameter of the pores associated with the mesopore area was calculated using the BJH method. This calculation assumes that $S_{\text {ext }}$ arises only from the pores and ignores contributions (expected to be small) from the external surface of zeolite crystallites. The calculations reveal that the average pore diameter of the mesopores increased substantially on both dealumination and desilication. This increase is probably due to the creation of new mesopores inside the zeolite crystallites and fusion of smaller pores into larger pores.

2.6. Acidity of Parent and Modified Samples from TPD of $\mathrm{NH}_{3}$. The ammonia TPD profiles of parent and modified samples are shown in Figure 4A-C. The acidity of the dealuminated BEA samples was determined by the TPD of $\mathrm{NH}_{3}$ (Figure 4A). The results are presented in Table 4. As the number of acid sites (total acidity) in a zeolite depends upon its $\mathrm{Al}$ content (one acid site per $\mathrm{Al}$ atom), a reduction in acidity is expected to occur on dealumination. This is found to be so in the case of the dealuminated BEA samples (Table 4). However, as seen from the table, the amount ( $\mathrm{mmol})$ of $\mathrm{NH}_{3}$ desorbed is much more than the amount $(\mathrm{mmol})$ of $\mathrm{Al}$ present in the samples. This is because the total amount of $\mathrm{NH}_{3}$ desorbed has been calculated from the total area under the desorption curve, and this includes physically adsorbed $\mathrm{NH}_{3}$ too. Although TPD measurements cannot identify the nature or type (Lewis or Brønsted), Marques has reported the presence of equal amounts of Lewis and Brønsted sites in the same commercial sample used by us (CP814E supplied by Zeolyst). ${ }^{23}$ In addition, the acidities of the desilicated and metal-exchanged BEA samples are shown in Figure 4B,C, and the results are displayed in Table 4.

2.7. ${ }^{27} \mathrm{Al}$ MAS NMR Spectrum of $\mathrm{BEA}(25)$. The ${ }^{27} \mathrm{Al}$ MAS NMR spectra of the parent zeolite $(\mathrm{BEA}(25))$ are presented in Figure S1. ${ }^{27} \mathrm{Al}$ NMR characterization of zeolites can reveal the nature of the $\mathrm{Al}$ species, especially the presence or absence of extraframework (non-Td) Al species. In the case of the present sample, although the majority of $\mathrm{Al}$ is in $\mathrm{Td}$ coordination (52.8 ppm; mostly in the framework), a significant amount of $\mathrm{Al}$ is found to be present in $\mathrm{Oh}$ 

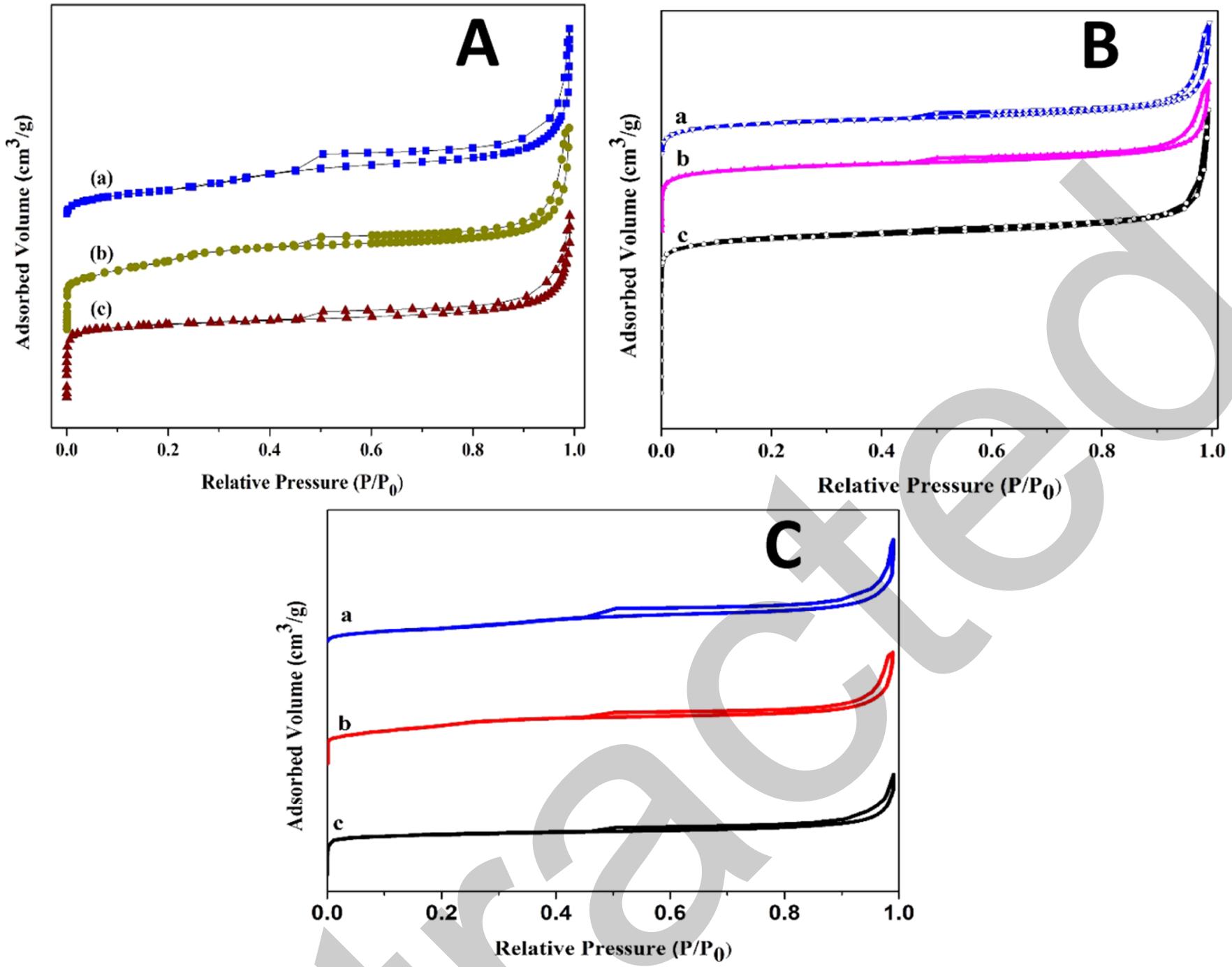

Figure 3. $\mathrm{N}_{2}$ adsorption-desorption isotherms of (A) dealuminated BEA samples, (B) desilicated BEA samples, and (C) metal-loaded BEA samples.

Table 3. Surface Areas and Pore Volumes of the Parent BEA and Dealuminated, Desilicated, and Metal-Exchanged BEA Samples

\begin{tabular}{|c|c|c|c|c|c|c|c|}
\hline \multirow[b]{2}{*}{ sample code } & \multirow[b]{2}{*}{ BET } & \multicolumn{2}{|c|}{ surface area $\left(\mathrm{m}^{2} / \mathrm{g}\right)$} & \multicolumn{3}{|c|}{ pore volume $\left(\mathrm{cm}^{3} / \mathrm{g}\right)$} & \multirow[b]{2}{*}{ mesopore dia. $(\AA)$} \\
\hline & & $t$-plot (micropore) & external area (meso) & total & $t$-plot (micropore) & mesopore & \\
\hline $\operatorname{BEA}(25)$ & 427 & 269 & 158 & 0.74 & 0.13 & 0.61 & 153 \\
\hline $\mathrm{BEA}(58)$ & 354 & 221 & 133 & 0.75 & 0.11 & 0.64 & 192 \\
\hline $\mathrm{BEA}(88)$ & 302 & 160 & 142 & 0.73 & 0.08 & 0.65 & 184 \\
\hline $\mathrm{BEA}(170)$ & 436 & 285 & 151 & 0.78 & 0.14 & 0.65 & 172 \\
\hline $\mathrm{BEA}(\mathrm{DS} 1)$ & 425 & 289 & 136 & 0.78 & 0.14 & 0.64 & 188 \\
\hline BEA(DS2) & 413 & 237 & 176 & 0.50 & 0.11 & 0.39 & 88 \\
\hline BEA-Fe & 450 & 270 & 180 & 0.78 & 0.15 & 0.63 & 165 \\
\hline BEA-Zn & 435 & 260 & 175 & 0.66 & 0.13 & 0.53 & 152 \\
\hline BEA-Ce & 405 & 245 & 160 & 0.58 & 0.12 & 0.46 & 98 \\
\hline
\end{tabular}

coordination $(\delta \sim 0 \mathrm{ppm})$ also, suggesting the presence of extraframework $\mathrm{Al}$ and probably amorphous material too.

\section{HYDROGENATION OF ANISOLE AND ACETOPHENONE HYDROGENATION STUDIES}

Studies on the hydrogenation of anisole and a model aromatic ketone, acetophenone, were carried out to check the possibility of carrying out the hydrogenation of the long-chain ketone formed in the acylation reaction to produce a long-chain alkyl aromatic compound (lauryl benzene; $n$-dodecylbenzene) in a single step in the presence of excess anisole. Sulfonic acid derivatives of such long-chain $n$-alkylbenzenes are expected to be useful as highly biodegradable detergents.

The studies were carried out using three supported metal catalysts: 0.5 wt $\% \mathrm{Pd} / \mathrm{BEA}(58), 0.5$ wt $\% \mathrm{Ru} / \mathrm{BEA}(58)$, and 0.5 wt $\% \mathrm{Pd} / \mathrm{NaY}(5.1)$. Two different metals and two different 

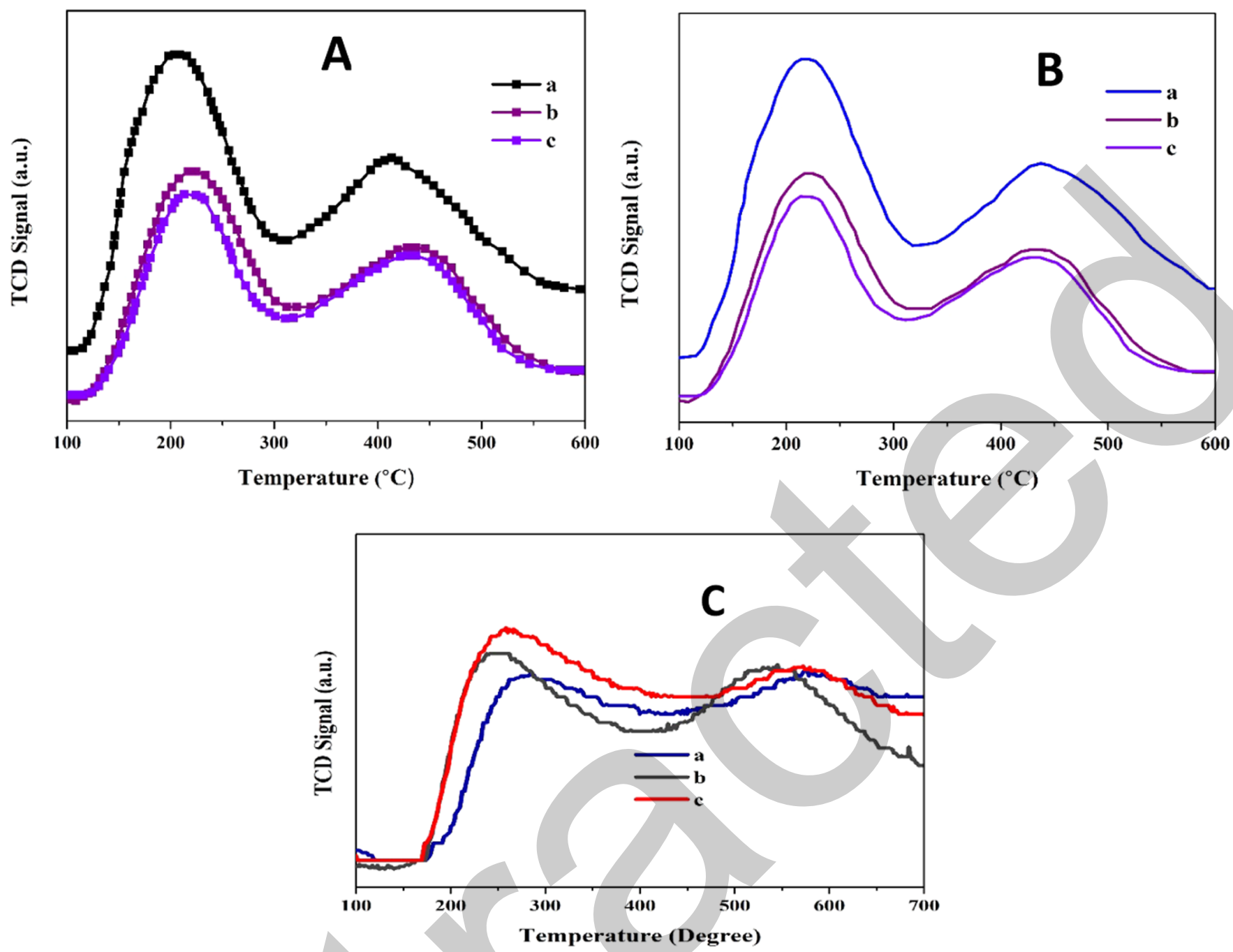

Figure 4. TPD profiles of (A) dealuminated BEA samples, (B) desilicated BEA samples, and (C) metal-loaded BEA samples.

Table 4. Acidities of the Parent BEA and Dealuminated, Desilicated, and Metal-Exchanged BEA from TPD of $\mathrm{NH}_{3}$

\begin{tabular}{lccc} 
sample & $\mathrm{SAR}\left(\mathrm{SiO}_{2} / \mathrm{Al}_{2} \mathrm{O}_{3}\right)$ & $\mathrm{Al}(\mathrm{mmol} / \mathrm{g})$ & acidity $\left(\mathrm{mmol} \mathrm{NH}_{3}\right) / \mathrm{g}$ \\
$\mathrm{BEA}(25)$ & 58 & 0.6 & 2.6 \\
$\mathrm{BEA}(58)$ & 83 & 0.9 & 2.1 \\
$\mathrm{BEA}(88)$ & 170 & 0.2 & 1.2 \\
$\mathrm{BEA}(170)$ & 64 & 0.8 & 2.7 \\
$\mathrm{BEA}(\mathrm{DS} 1)$ & 78 & 0.9 & 2.3 \\
$\mathrm{BEA}(\mathrm{DS} 2)$ & 160 & 0.6 & 1.9 \\
$\mathrm{BEA}-\mathrm{Fe}$ & 91 & 0.6 & 2.8 \\
BEA-Zn & 105 & 0.9 & 2.6 \\
BEA-Ce & 168 & 0.4 & 1.8 \\
\hline
\end{tabular}

supports with different hydrogenation characteristics and acidic-basic properties have been studied. The basic Na$\mathrm{Y}(5.1)$ and acidic $\mathrm{BEA}(58)$ supports are expected to have different effects on the hydrogenation activity of the metal function through different metal-support interactions (Figure 5)..$^{35}$

3.1. Hydrogenation of Anisole. The hydrogenation of anisole is expected to yield methoxy cyclohexanone. The conversion of anisole with the duration of run over the three catalysts is presented in Figure 6. Product analysis of the reaction mixture (Table 5) does not reveal the formation of the

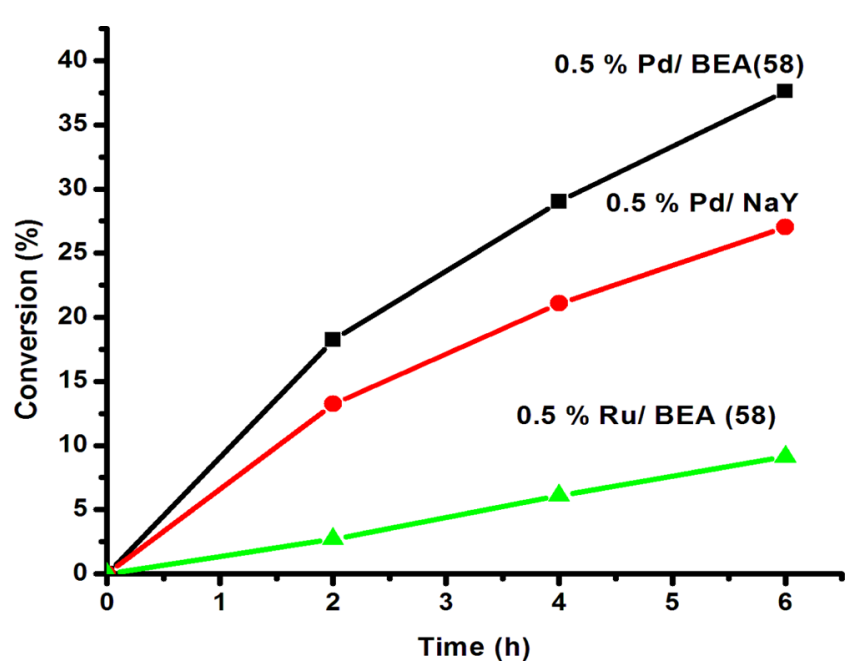

Figure 5. Hydrogenation of anisole at pressure $\left(\mathrm{H}_{2}\right)=25$ bar, temperature $=155^{\circ} \mathrm{C}, 500 \mathrm{mg}$ of catalyst, and $400 \mathrm{RPM}$.

expected methoxy cyclohexanone. ${ }^{37,38}$ The major reaction is the formation of phenol through cleavage of the $-\mathrm{O}-\mathrm{Me}$ ether linkage; hydrogenation of the phenol leads to the formation of cyclohexanol and its subsequent dimerization, as 


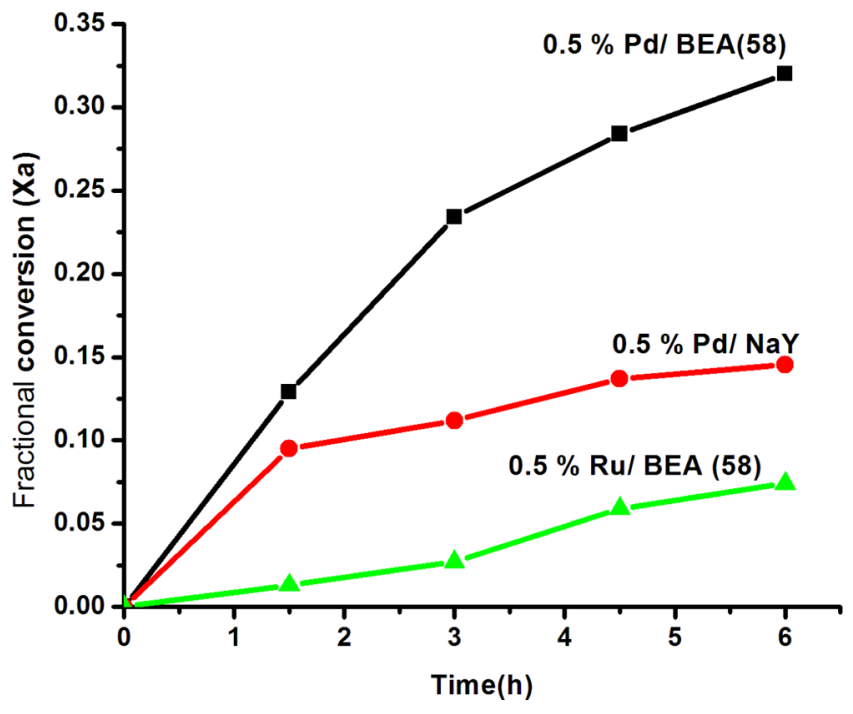

Figure 6. Hydrogenation of acetophenone: pressure $=25$ bar $\left(\mathrm{H}_{2}\right)$; temp $=155{ }^{\circ} \mathrm{C} ; 500 \mathrm{mg}$ of catalyst; $400 \mathrm{RPM}$.

shown in Figure S2. During the dimerization reaction over the acid catalyst, dehydration from cyclohexanol leads to the production of cyclohexene. Then, the reaction between the cyclohexene and the anion of cyclohexanol leads to formation of cyclohexylidene and cyclohexylidene derivative. An examination of Figure 3 and Table 5 reveals that $\mathrm{Pd} /$ $\mathrm{BEA}(58)$ is more active than $\mathrm{Pd} / \mathrm{NaY}(5.1) . \mathrm{Ru} / \mathrm{BEA}(58)$ is the least active. However, interestingly, the dimerization reaction (to produce 2-cyclohexylcyclohexanone) is very small over the $\mathrm{NaY}(5.1)$ catalyst, revealing that acid sites are necessary for dimerization of the cyclohexanol formed. The $\mathrm{Ru} / \mathrm{BEA}(58)$ does not also produce the dimeric ketone because it does hydrogenate the intermediate phenol into cyclohexanol. Similar results have already been reported by earlier workers. ${ }^{39}$

3.2. Hydrogenation of Acetophenone. Acetophenone was chosen as the model compound to check its hydrogenation characteristics. The results of these studies are presented in Figure 6 and Table S1. The studies reveal that the activity of the three catalysts is in the same order as observed in the hydrogenation of anisole; the activity decreases in the order $\operatorname{Pd}-\mathrm{BEA}(58)>\operatorname{Pd}-\mathrm{NaY}(5.1)>\mathrm{Ru}-\mathrm{BEA}(58)$.

The main product of hydrogenation of acetophenone is ethylbenzene in the case of the acidic support, BEA(58) and phenylethane in the case of the basic support, $\mathrm{NaY}(5.1)$.

The studies reveal that it is possible to carry out the hydrogenation of ketone to alkyl benzene using Pd-BEA catalysts. However, carrying out the reaction in the presence of anisole does not appear to be possible as anisole undergoes conversion into numerous unwanted products. Hence, the idea of carrying out the acylation and hydrogenation reactions in a single pot does not appear to be feasible in this case, although ketone can be hydrogenated after removal of anisole from the reaction mixture. ${ }^{40,41}$

3.3. Comparison of the Initial Reaction Rates over Different Catalysts. To study the relative rates of acylation and hydrogenation reactions (at the conditions of the experiments), the initial rates at $0 \mathrm{~h}$ obtained from extrapolation of the data presented in earlier sections are presented in Table S2. The results show that the hydrogenation of anisole is much faster than the acylation reaction. ${ }^{42}$ The rate of hydrogenation of acetophenone is on the same order as that of anisole. In the case of the large-molecularweight ketone formed with lauric acid and anisole [1-(4methoxyphenyl)dodecane-1-one], the rate is expected to be lower because of a steric hindrance as it is associated with an aromatic ring on one side and a long-chain paraffin on the other side. Hence, when hydrogenation of ketone is attempted in a single-pot reaction, anisole is likely to get hydrogenated faster than the ketone (which is also in low concentration in the reaction mixture). Hence, when a single-pot acylation-cumhydrogenation is carried out over Pd-BEA, the most likely reaction will be the transformation of anisole into many unwanted products instead of its acylation or the subsequent hydrogenation of ketone. As predicted, when a single-pot acylation-cum-hydrogenation was carried out over $0.5 \% \mathrm{Pd}$ $\mathrm{BEA}(58)$, no acylated product was formed; only the typical products formed during the hydrogenation of anisole were found. $^{43,44}$

\section{CONCLUSIONS}

It has been planned to carry out a combined acylation-cumhydrogenation reaction to prepare $n$-dodecylbenzene on $\mathrm{Ru}$ and Pd-supported modified zeolite materials. When an experiment was performed using 0.5 wt $\% \mathrm{Pd} / \mathrm{BEA}(58)$ catalyst at $155^{\circ} \mathrm{C}$ under $25 \mathrm{bar}_{2}$ pressure, acylation products were not obtained. This reaction was then investigated by carrying out separate experiments on hydrogenation of anisole and a model aromatic ketone, acetophenone, at the same conditions. To study the effect of the metal and the acidicbasic nature of the support, three different catalysts were prepared with $\mathrm{Pd}$ and $\mathrm{Ru}$ as the metals as well as $\mathrm{BEA}(58)$ (acidic support) and $\mathrm{NaY}$ (basic support). The studies revealed that the reaction on the acidic support, anisole, underwent hydrogenolysis to yield the ether, which then underwent hydrogenation into cyclohexanol and dimerization over the acid sites. This dimerization reaction did not occur over the basic support. However, hydrogenation of ketone into ethylbenzene took place with good selectivity over $\mathrm{Pd} /$ $\operatorname{BEA}(58)$. These studies point out that it is not possible to carry out the acylation of anisole and hydrogenation of ketone in a single pot and that ketone will need to be separated from anisole prior to its hydrogenation. Summing up, the studies reveal that BEA modified by mild dealumination/desilication is

Table 5. Product Distribution in Hydrogenation of Anisole over Different Catalysts

\begin{tabular}{cccccc} 
& \multicolumn{4}{c}{ product distribution (area \%) } \\
\cline { 2 - 5 } samples $^{a}$ & phenol & cyclohexanol & dimeric ketone & others \\
$0.5 \% \mathrm{Pd} / \mathrm{BEA}(58)$ & 8.2 & 17.8 & 69.4 & 4.6 \\
$0.5 \% \mathrm{Pd} / \mathrm{NaY}(5.1)$ & 3.1 & 77.9 & 5.7 & 37.6 \\
$0.5 \% \mathrm{Ru} / \mathrm{BEA}(58)$ & 66.3 & 2.2 & 27.1 & 13.3
\end{tabular}

${ }^{a}$ Pressure $=25$ bar $\left(\mathrm{H}_{2}\right)$; temp $=155^{\circ} \mathrm{C} ; 500 \mathrm{mg}$ of catalyst; $400 \mathrm{RPM}$; time $=6 \mathrm{~h}$. 
suitable for the acylation of anisole with long-chain acids. Also, acylation over BEA produces mainly the $p$-acylated product (ketone), which is often the desired product. $\mathrm{Pd} / \mathrm{BEA}$ is a good catalyst for the hydrogenation of ketone to alcohol (another desired product) or the alkyl aromatic hydrocarbon.

\section{EXPERIMENTAL SECTION}

5.1. Zeolite Characterization Techniques. To comprehend the chemistry happening in catalysis, it is essential to have knowledge of the physical and chemical characteristics of zeolite catalysts. To study the structure and characteristics of the $\beta$-zeolite catalysts, characterization methods were used. $\mathrm{X}$ ray powder diffraction (XRD), magic angle spinning nuclear magnetic resonance $\left({ }^{27} \mathrm{Al}\right.$ MAS NMR), nitrogen adsorption, and temperature-programmed desorption (TPD) were used to analyze the catalyst sample.

5.2. Chemicals and Instrument Used. The $\beta$-zeolite (Zeolyst International; CP814E), tetrapropylammonium hydroxide (TPAOH) (TCI Chemicals), sodium hydroxide (SRL Chemicals), nitric acid (Merck), cerium(III) nitrate ( $\mathrm{CDH}$ chemicals), zinc nitrate hexahydrate (Merck), iron(III) nitrate nonahydrate (Sigma Aldrich), tetraamine palladium(II) chloride monohydrate (AR, Sigma Aldrich Chemicals), ruthenium trichloride hexahydrate (AR, Sigma Aldrich Chemicals), lauric acid (Loba Chemicals), anisole (Merck), acetophenone (Merck), and $\mathrm{NaY}(5.1)$ (Zeolyst International; CBV100) were used as procured. X-ray diffraction (XRD) patterns for the calcined materials were obtained using a Rigaku Miniflex II with $\mathrm{Cu} \mathrm{K} \alpha$ irradiation in the $2 \theta$ range of $5-80^{\circ}$ with a scan step size of $0.02^{\circ}$. BET surface areas, $t$-plot analysis, and pore volume measurements were carried out by $\mathrm{N}_{2}$ adsorption (at Liq. $\mathrm{N}_{2}$ temperature) using a Micromeritics (ASAP 2010) instrument. The acidity of the catalysts was determined using temperature-programmed desorption (TPD) of $\mathrm{NH}_{3}$ (AutoChem 2910, Micromeritics) using a $5 \% \mathrm{NH}_{3}$ and $95 \%$ argon gas mixture. Before the TPD analysis, $0.05 \mathrm{~g}$ of the sample was pretreated at $400{ }^{\circ} \mathrm{C}$ for $2 \mathrm{~h}$ under a He flow $(80$ $\mathrm{mL} / \mathrm{min}$ ). The $\mathrm{Si}$ and $\mathrm{Al}$ ratios of the calcined materials were determined by an X-ray fluorescence spectrometer on a Rigaku ZSX-100e instrument.

The liquid product of the Friedel-Crafts acylation was analyzed by gas chromatography (MICHRO 9100) using an FID detector and a BPX $70(30 \mathrm{~m} \times 0.53 \mathrm{~mm})$ column.

5.3. Preparation of Catalysis. In this work, commercial $\beta$ zeolite (BEA) was modified to increase the activity in the acylation reaction. Metals like Pd and Ru were loaded on BEA and $\operatorname{NaY}(5.1)$ to study the hydrogenation of ketone and anisole.

5.4. Dealumination Procedure. Dealuminated samples of BEA were prepared from parent $\beta \operatorname{BEA}(25) \cdot \operatorname{BEA}(25)$ (5 g) was dealuminated by treating it with different concentrations of $\mathrm{HNO}_{3}$ (60 g of acid per gram of zeolite) at two time intervals ( 1 and $6 \mathrm{~h}$ ) and two temperatures (298 and $358 \mathrm{~K}$ ). To remove leftover acid and free aluminum species, the dealuminated samples were washed twice with distilled water followed by dilute ammonia solution ( $6 \mathrm{wt} \%)$. The materials were filtered and dried for $6 \mathrm{~h}$ at $373 \mathrm{~K}$. Prior to use in the acylation reaction experiments, all samples were calcined in air for $6 \mathrm{~h}$ at $723 \mathrm{~K}$. The temperature of the calcination was gradually raised from room temperature to $723 \mathrm{~K}^{31}$ All of the samples were characterized by XRD to confirm that the $\beta$ zeolite structure was maintained after dealumination. The samples obtained are referred to as $\operatorname{BEA}(58), \operatorname{BEA}(88)$, and
$\mathrm{BEA}(170)$, in which the number refers to the $\mathrm{SiO}_{2} / \mathrm{Al}_{2} \mathrm{O}_{3}$ ratio of the sample. The conditions of preparation of the different dealuminated samples are presented in Table 6.

Table 6. Conditions Used in the Dealumination of $\beta$

\begin{tabular}{lccc}
\multicolumn{1}{c}{ sample code } & conc. of nitric acid (\%) & temperature (K) & time $(\mathrm{h})$ \\
parent BEA(25) & & & \\
BEA $(58)$ & 10 & 298 & 1 \\
BEA $(88)$ & 10 & 298 & 6 \\
BEA(170) & 55 & 358 & 6 \\
\hline
\end{tabular}

5.5. Desilication Procedure. While acid treatment removes $\mathrm{Al}$ species (from the framework and other positions), alkali treatment removes $\mathrm{Si}$ (desilication). Alkaline treatment was carried out in a round-bottomed flask with different volumes (30 and $20 \mathrm{~mL}$ ) of $0.5 \mathrm{M}$ aqueous solution of tetrapropylammonium hydroxide (TPAOH) at two different temperatures ( 333 and $343 \mathrm{~K}$ ). BEA(25) ( $2 \mathrm{~g}$ ) was added to a continuously stirred mixture of TPAOH kept at the required temperature. The mixture was treated for $4 \mathrm{~h}$, and the resulting sample was washed with distilled water until neutral $\mathrm{pH}$, filtered, dried at $373 \mathrm{~K}$ for $12 \mathrm{~h}$, and calcined at $723 \mathrm{~K}$ for $4 \mathrm{~h}$. The samples are referred to as BEA(DS1) and BEA(DS2). The condition employed to prepare these samples are given in Table $7 .^{32}$

Table 7. Conditions of Desilication

$\begin{array}{lccc}\text { sample code } & \text { conc. of TPAOH acid } & \text { temperature }(\mathrm{K}) & \text { time }(\mathrm{h}) \\ \text { parent BEA(25) } & & & \\ \text { BEA(DS1) } & 30 \mathrm{~mL}(0.5 \mathrm{M}) & 343 & 4 \\ \text { BEA(DS2) } & 20 \mathrm{~mL}(0.5 \mathrm{M}) & 333 & 4\end{array}$

5.6. Catalyst Preparation for the Hydrogenation

Reaction. $\mathrm{Pd}, \mathrm{Pt}, \mathrm{Ru}$, and $\mathrm{Ni}$ are often used for the hydrogenation of organic compounds. In this study, hydrogenation of anisole and acetophenone was done using $\mathrm{Pd}$ and $\mathrm{Ru}$ supported on an acidic support $(\mathrm{BEA}(58))$ and a basic support $(\mathrm{NaY}(5.1))$. The supports were loaded with the metal salts by a wet impregnation procedure. ${ }^{33}$

5.7. Impregnation with Pd. Palladium was loaded on $\mathrm{BEA}(58)$ by a wet impregnation method using a solution of $\left(\mathrm{Pd}\left(\mathrm{NH}_{3}\right)_{4} \mathrm{Cl}_{2}\right)$. The required amount of salt (to yield $0.5 \mathrm{wt}$ $\% \mathrm{Pd}$ loading) was dissolved in $5 \mathrm{~mL}$ of water, followed by the addition of $1.5 \mathrm{~g}$ of $\operatorname{BEA}(58)$. The mixture was stirred for $1 \mathrm{~h}$ at $30{ }^{\circ} \mathrm{C}$. The impregnated sample thus obtained was dried overnight at $100{ }^{\circ} \mathrm{C}$. Finally, the Pd salt-loaded BEA(58) was calcined at $400{ }^{\circ} \mathrm{C}$ for $4 \mathrm{~h}$. A similar procedure was used to load $0.5 \% \mathrm{Pd}$ on $\mathrm{NaY}$.

5.8. Impregnation with $\mathrm{Ru}$. $\mathrm{RuCl}_{3}$ was utilized as a source of $\mathrm{Ru}$ species in this experiment. $\mathrm{RuCl}_{3}$ was dissolved in $5 \mathrm{~mL}$ of water, followed by the addition of $1.5 \mathrm{~g}$ of $\mathrm{BEA}(58)$. The mixture was stirred for $1 \mathrm{~h}$ at $30{ }^{\circ} \mathrm{C}$. The impregnated sample thus obtained was dried overnight at $100{ }^{\circ} \mathrm{C}$. Finally, it was calcined at $400{ }^{\circ} \mathrm{C}$ for $4 \mathrm{~h}$. The amount of $\mathrm{RuCl}_{3}$ taken was calculated to produce a loading of $0.5 \mathrm{wt} \%$ of $\mathrm{Ru}$.

5.9. Product Identification. Products were identified by injecting standards for phenol and methanol, while the ketone was identified by ${ }^{1} \mathrm{H}$ NMR. The pure ketone was obtained from the reaction mixture by the following procedure: the catalyst was separated from the reaction mixture by filtration and dissolved in ether, and the acid and phenol were removed 
from the reaction mixture by extraction with sodium hydroxide. The organic layer was separated. Diethyl ether was removed by evaporation, while anisole was removed by distillation. Finally, the product was purified by column chromatography using a $\mathrm{SiO}_{2}$ gel 100-200 mesh and chloroform.

5.10. Hydrogenation of Anisole and Acetophenone Procedure. Hydrogenation reactions were carried out in a Parr reactor $(100 \mathrm{~mL})$ as shown in Figure 7 . Hydrogenation of

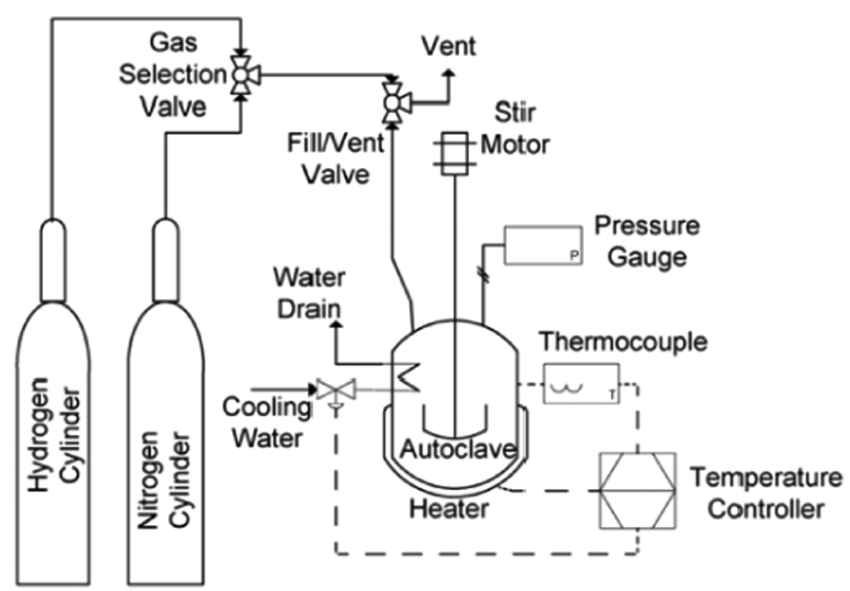

Figure 7. Pictorial representation of the batch reactor used.

anisole and acetophenone was done at $155^{\circ} \mathrm{C}$ and 25 bar $\mathrm{H}_{2}$ pressure in the presence of $\mathrm{Pd} / \mathrm{BEA}(58), \mathrm{Pd} / \mathrm{NaY}(5.1)$, and $\mathrm{Ru} / \mathrm{BEA}(58)$. All of the catalysts were reduced in the $\mathrm{H}_{2}$ atmosphere at $400{ }^{\circ} \mathrm{C}$ for $4 \mathrm{~h}$ before the reaction. The catalysts were reduced in a tubular furnace and cooled in hydrogen, followed by $\mathrm{N}_{2}$ flushing. The reduced sample kept in a boat was quickly transferred to the Parr reactor, and the hydrogenation was carried out. At the end of the reaction, the reaction mixture was filtered off to remove the catalyst. The products were analyzed in a gas chromatograph. The hydrogenation of anisole and acetophenone was carried out on three metal-loaded samples at 25 bar and $155^{\circ} \mathrm{C}$ in a Parr $(330 \mathrm{~mL})$ autoclave. The results of the studies are described below.

\section{ASSOCIATED CONTENT}

\section{Supporting Information}

The Supporting Information is available free of charge at https://pubs.acs.org/doi/10.1021/acsomega.1c03566.

${ }^{27} \mathrm{Al}$ spectra of the parent BEA (Figure $\mathrm{S} 1$ ), scheme for formation of the observed products in the hydrogenation of anisole (Figure S2), product distribution of hydrogenation of acetophenone over different catalysts, and comparison of the initial rates for acylation and hydrogenation reactions (Tables S1 and S2) (PDF)

\section{AUTHOR INFORMATION}

\section{Corresponding Authors}

Tamizhdurai Perumal - Department of Chemistry, Dwaraka Doss Goverdhan Doss Vaishnav College (Autonomous) (Affiliated to the University of Madras, Chennai), Chennai 600106 Tamil Nadu, India; (1) orcid.org/0000-0002-79557287; Email: tamizhvkt2010@gmail.com; Fax: +919677146579
Ayman A. Ghfar - Advanced Materials Research Chair, Chemistry Department, College of Science, King Saud University, Riyadh 11451, Saudi Arabia; Email: Aghafr@ ksu.edu.sa

\section{Authors}

V. L. Mangesh - Sathyabama Institute of Science and Technology, Chennai 600119, India

Santhana Krishnan Perumal - Department of Chemistry, Anna University, Chennai 600025, India

Kumaran Rajendran - Department of Chemistry, Dwaraka Doss Goverdhan Doss Vaishnav College (Autonomous) (Affiliated to the University of Madras, Chennai), Chennai 600106 Tamil Nadu, India; 10 orcid.org/0000-0002-53584447

Narayanan Subramanian - Sriram College of Arts and Science, Tiruvallur, Tamil Nadu 602024, India; - orcid.org/0000-0002-3757-7140

Mani Govindasamy - Department of Materials and Minerals Engineering, National Taipei University of Technology, Taipei 10608, Taiwan

Murefah mana AL-Anazy - Department of Chemistry, College of Science, Princess Nourah bint Abdulrahman University, Riyadh 11671, Saudi Arabia

Mohamed Ouladsmane - Advanced Materials Research Chair, Chemistry Department, College of Science, King Saud University, Riyadh 11451, Saudi Arabia

Complete contact information is available at:

https://pubs.acs.org/10.1021/acsomega.1c03566

\section{Notes}

The authors declare no competing financial interest.

\section{ACKNOWLEDGMENTS}

The authors are grateful to the Deanship of Scientific Research, King Saud University for funding through the Vice Deanship of Scientific Research Chairs. This research was also funded by the Deanship of Scientific Research at Princess Nourah bint Abdulrahman University through the Fast-track Research Funding Program.

\section{REFERENCES}

(1) Absil, R.; Hatzikos, G. H. Hydrocarbon Conversion Process Using Zeolite Beta Catalysts. U.S. Patent 5,833,840, 1998.

(2) Aguilar, J.; Corma, A.; Melo, F.; Sastre, E. Alkylation of biphenyl with propylene using acid catalysts. Catal. Today 2000, 55, 225-232.

(3) Anonymous. US Zeolite Market Set to Reach \$1 Billion in 2001, Study Says. Chemical Market Reporter; Schnell Publishing Company: New York, 1996.

(4) Anonymous. D458, Zeolite, Industry Trends and Worlwide Markets in 2010. Frost Sullivan, 2001.

(5) Bagnasco, G. Improving the Selectivity of $\mathrm{NH}_{3}$ TPD measurements. J. Catal. 1996, 159, 249-252.

(6) Barrer, R. Hydrothermal Chemistry of Zeolites; Academic Press: London, 1982.

(7) Bell, A.; Pines, A. NMR Techniques in Catalysis; Marcel Dekker, Inc, 1994.

(8) Botella, P.; A Corma, A.; Lopez-Nieto, M.; Valencia, S.; Jacquoty, R. Acylation of Toluene with Acetic Anhydride over Beta Zeolites: Influence of Reaction Conditions and Physicochemical Properties of the Catalyst. J. Catal. 2000, 195, 161-168.

(9) Choudary, B. M.; Mutyala, S.; Mannepalli, L.; Kompella, V. Acylation of aromatic ethers with acid anhydrides in the presence of cation-exchanged clays. Appl. Catal., A 1998, 171, 155-160. 
(10) Breck, D. Zeolite Molecular Sieves, Structure, Chemistry and Use; John Wiley and Sons: New York, 1974.

(11) Brunauer, S.; Emmett, P. H.; Teller, E. J. Am. Chem. Soc. 1938, 60, 309.

(12) Casagrande, M.; Storaro, I.; Lenarda, M.; Ganzerla, R. Highly Selective Friedel-Crafts Acylation of 2-metoxynaphthalene catalysed by H-BETA Zeolite. Appl. Catal., A 2000, 201, 263-270.

(13) Charles, S. Heterogeneous Catalysis in Industrial Practise, 2nd ed.; McGraw-Hill Inc., 1991.

(14) Chiu, J.; Pine, D.; Bishop, S.; Chmelka, B. Friedel-Crafts alkylation properties of aluminosilica SBA-15 meso/macroporous monoliths and Jamesoporous powders. J. Catal. 2004, 221, 400-412.

(15) Corma, A.; Climent, J.; Garcia, H.; Primo, J. Design of Synthetic Zeolites as Catalysts in Organic Reactions. Acylation of Anisole by Acyl Chlorides or Carboxylic Acids over Acid Zeolites. Appl. Catal. A. 1989, 49, 109-123.

(16) Costa, C.; Dzikh, P.; Lopes, J.; Lemos, F.; Ribeiro, R. Activity acidity relationship in zeolite ZSM-5. Application of Brønsted-type equations. J. Mol. Catal. A: Chem. 2000, 154, 193-201.

(17) Flanigen, E. M. Zeolite and Molecular Sieve an Historical Perspective. In Studies in Surface Science and Catalysis; Elsevier, 1991; Vol. 58, pp 13-34.

(18) Gregg, S.; Sing, W. Adsorption Surface Area and Porosity; Academic Press: London, 1982; Chapter 4.

(19) Higgins, J.; La Pierre, R.; Schlenker, J.; Rohrman, A.; Wood, J.; Kerr, G.; Rohrbaugh, W. The Framework Topology of Zeolite Beta. Zeolites 1988, 8, 446-452.

(20) Heroshi, Y.; Mitsukura, Y.; Kobashi, H. Microwave-assisted acylation compounds using carboxylic acids and Zeolite catalysts. $J$. Mol. Catal. A: Chem. 2010, 322, 80-86.

(21) Hölderich, W. F.; Röseler, J.; Heitmann, G.; Liebens, A. The use of zeolites in the synthesis of fine and intermediate chemicals. Catal. Today 1997, 37, 353-366.

(22) Jansen, J.; Creighton, E.; Njo, S.; Koningsveid, H.; Bekkum, H. On the Remarkable Behavior of Zeolite Beta in Acid Catalysis. Catal. Today. 1997, 38, 205-212.

(23) Marques, J. P.; Gener, I.; Ayrault, P.; Bordado, C.; Lopes, M.; Ramôa Ribeiro, F.; Guisnet, M. Infrared spectroscopic studies of the acid properties of dealuminated BEA zeolites. Microporous Mesoporous Mater. 2003, 60, 251-262.

(24) Matias, P.; S'a Couto, I.; Grac, a.; Lopes, M.; Carvalho, P.; Ribeiro, R. F.; Guisnet, M. Appl. Catal., A. 2011, 399, 100-109.

(25) Meier, W.; Olson, D.; Boerlocher, C. Atlas of Zeolite Structure Types, 4th ed.; International Zeolite Association: Amsterdam, 1996.

(26) Narayanan, S.; Murthy, K. Montmorillonite as a versatile solid acid catalyst for tert-butylation of resorcinol. Appl. Catal., A 2001, 213, 273-278.

(27) Nivarthy, G.; Seshan, K.; Lercher, J. The influence of acidity on zeolite H-BEA catalyzed isobutene/n-butene alkylation. Microporous Mesoporous Mater. 1998, 22, 379-388.

(28) Roland, E.; Kleinschmit, P. Ullman's Encyclopedia of Industrial Chemistry; VCH Verlagsgesellschaft, 1996; Vol. 28, pp 475-504.

(29) Treacy, M.; Higgins, J.; Ballmoos, R. Collection of Simulated XRD Powder Patterns for Zeolites, 3rd ed.; Elsevier: Amsterdam, 1996. (30) Jacobs, P. A.; Flanigen, E. M.; Jansen, J. C.; van Bekkum, H. Introduction to Zeolite Science and Practice, 2nd ed.; Elsevier: Amsterdam, 2001.

(31) Wadlinger, R.; Kerr, G.; Rosinski, E. Catalytic Composition of a Crystalline Zeolite. US Patent 3,308,0691967.

(32) Wagholikar, S. G.; Niphadkar, S.; Mayadevi, S.; Sivasanker, S. Acylation of anisole with long-chain carboxylic acids over wide pore zeolites. Appl. Catal., A 2007, 317, 250-257.

(33) Yadav, G.; Doshi, N. Alkylation of aniline with methyl-tert-butyl ether (MTBE) and tert-butanol over solid acids, product distribution and kinetics. J. Mol. Catal. A: Chem. 2003, 194, 195-209.

(34) Zaiku, X.; Jiaqing, B.; Yiqing, Y.; Qingling, C.; Chengfang, Z. Effect of treatment with $\mathrm{NaAlO}_{2}$ solution on the Surface Acid Properties of Zeolite $\beta$. J. Catal. 2002, 205, 58-66.
(35) Saha, B.; Bohn, C. M.; Abu-Omar, M. M. Zinc-assisted hydrodeoxygenation of biomass-derived 5-hydroxymethylfurfural to 2, 5-dimethylfuran. ChemSusChem 2014, 7, 3095-3101.

(36) Dong, F.; Ding, G.; Zheng, H.; Xiang, X.; Chen, L.; Zhu, Y.; Li, $\mathrm{Y}$. Highly dispersed $\mathrm{Cu}$ nanoparticles as an efficient catalyst for the synthesis of the biofuel 2-methylfuran. Catal. Sci. Technol. 2016, 6, 767-779.

(37) Meng, Q.; Hou, M.; Liu, H.; Song, J.; Han, B. Synthesis of ketones from biomass-derived feedstock. Nat. Commun. 2017, 8, No. 14190.

(38) Fujita, S. I.; Onodera, Y.; Yoshida, H.; Arai, M. Green Chem. 2016, 18, 4934-4940.

(39) Upare, P. P.; Jeong, M. G.; Hwang, Y. K.; Kim, D. H.; Kim, Y. D.; Hwang, D. W.; Lee, U. H.; Chang, J. S. Nickel-promoted coppersilica nanocomposite catalysts for hydrogenation of levulinic acid to lactones using formic acid as a hydrogen feeder. Appl. Catal., A 2015, 491, 127-135.

(40) Becheri, A.; Dürr, M.; Lo Nostro, P.; Baglioni, P. Synthesis and characterization of zinc oxide nanoparticles: application to textiles as UV-absorbers. J. Nanopart. Res. 2008, 10, 679-689.

(41) Barbera, K.; Lanzafame, P.; Pistone, A.; Millesi, S.; Malandrino, G.; Gulino, A.; Perathoner, S.; Centi, G. The role of oxide location in HMF etherification with ethanol over sulfated $\mathrm{ZrO} 2$ supported on SBA-15. J. Catal. 2015, 323, 19-32.

(42) Srivastava, S.; Jadeja, G.C.; Parikh, J. Synergism studies on alumina-supported copper-nickel catalysts towards furfural and 5hydroxymethylfurfural hydrogenation. J. Mol. Catal. A: Chem. 2017, $426,244-256$.

(43) El-Shobaky, H. G. Surface and catalytic properties of Co, Ni and $\mathrm{Cu}$ binary oxide systems. Appl. Catal., A 2004, 278, 1-9.

(44) Khromova, S. A.; Smirnov, A. A.; Bulavchenko, O. A.; Saraev, A. A.; Kaichev, V. V.; Reshetnikov, S. I.; Yakovlev, V. A. Appl. Catal., A 2014, 470, 261-270. 


\section{Effect of modified zeolite beta in the hydrogenation of anisole and acetophenone reaction}

V. L. Mangesh ${ }^{1}$, Tamizhdurai Perumal2*, Santhana Krishnan Perumal ${ }^{3}$, Kumaran Rajendran ${ }^{2}$, Narayanan Subramanian ${ }^{4}$, Mani Govindasamy ${ }^{5}$, Ayman A. Ghfar ${ }^{6 *}$, Murefah mana ALAnazy $^{7}$, Mohamed Ouladsmane ${ }^{6}$

${ }^{1}$ Sathyabama Institute of Science and Technology, Jeppiar Nagar, Chennai-600119, India ${ }^{2}$ Department of Chemistry, Dwaraka Doss Goverdhan Doss Vaishnav College (Autonomous) (Affiliated to the University of Madras, Chennai), 833, Gokul Bagh, E.V.R. Periyar Road, Arumbakkam, Chennai 600 106, Tamil Nadu, India ${ }^{3}$ Department of Chemistry, Anna University, Chennai 600 025, India

${ }^{4}$ Sriram College of Arts and Science, Perumalpattu, Veppampattu, Tiruvallur, Tamilnadu, 602 024, India

${ }^{5}$ Department of Materials and Minerals Engineering, National Taipei University of Technology,

\section{Taipei, Taiwan}

${ }^{6}$ Advanced Materials Research Chair, Chemistry Department, College of Science, King Saud University, Riyadh 11451, Saudi Arabia

${ }^{7}$ Department of Chemistry, College of Science, Princess Nourah bint Abdulrahman University, Riyadh 11671, Saudi Arabia

\section{* Corresponding authors:}

Dr. P.Tamizhdurai; Tel.:+91-9677146579; E-mail:tamizhvkt2010@gmail.com

Dr. Ayman A. Ghfar; E-mail address: Aghafr@ksu.edu.sa 


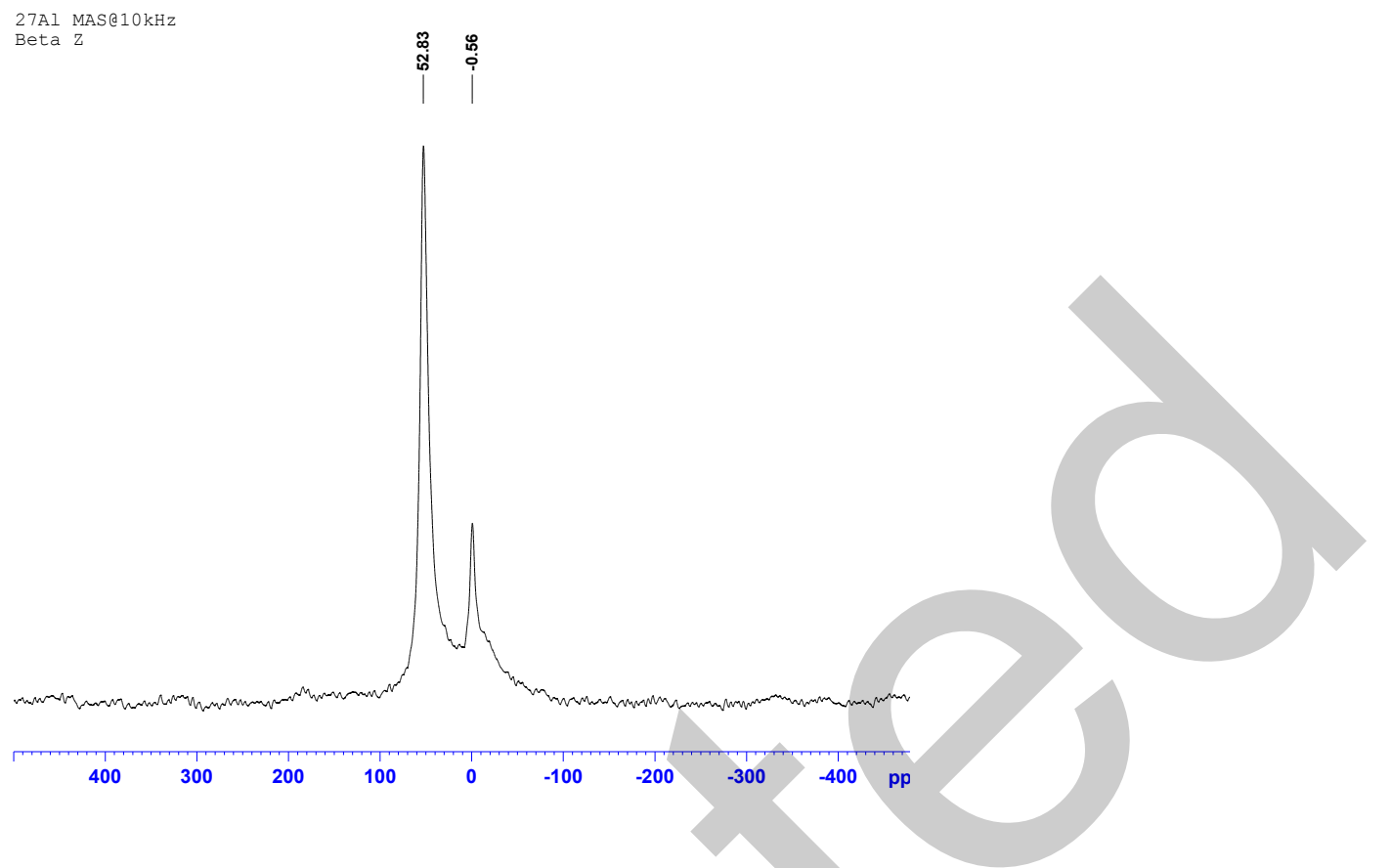

Figure S1. ${ }^{27} \mathrm{Al}$ spectra of the parent BEA used in the studies

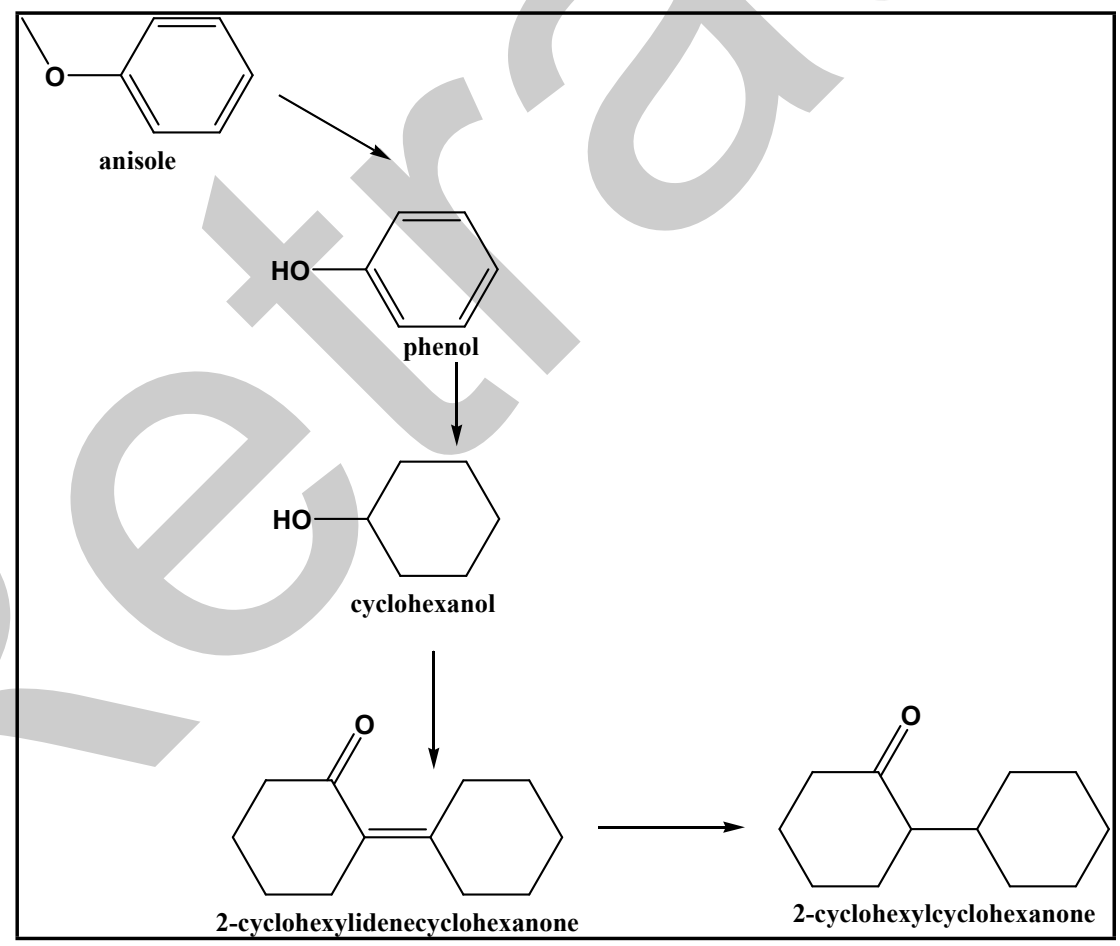

Figure S2.Scheme for formation of the observed products in the hydrogenation of anisole 
Table S1 Product distribution of hydrogenation of acetophenone over different catalyst

\begin{tabular}{|c|c|c|c|c|c|}
\hline \multirow{2}{*}{ Samples } & \multicolumn{3}{|c|}{ Product distribution (area \%) } & \multirow{2}{*}{ Conversion } \\
\cline { 2 - 5 } & $\begin{array}{c}\text { Ethyl } \\
\text { Benzene }\end{array}$ & $\begin{array}{c}\text { Phenyl } \\
\text { Ethanol }\end{array}$ & Toluene & others & (mole \%) \\
\cline { 1 - 5 } $\begin{array}{c}\text { 0.5\%Pd/ } \\
\text { BEA(58) }\end{array}$ & 61.4 & 13.5 & 7.0 & 18.1 & 32.0 \\
\hline $\begin{array}{c}\text { 0.5\% Pd/ } \\
\text { NaY(5.1) }\end{array}$ & 53.8 & 42.3 & 2 & 17.9 & 14.5 \\
\cline { 1 - 5 } 0.5\%Ru/BEA(58) & 70.2 & 17.9 & 0.9 & 11.6 & 7.4 \\
\hline
\end{tabular}

Press $=25$ bar $\mathrm{H}_{2}$; Temp $=155^{\circ} \mathrm{C} ; 500 \mathrm{mg}$ catalysts; $400 \mathrm{RPM}$; Time $=6 \mathrm{~h}$

Table S2. Comparison of the initial rates for acylation and hydrogenation reactions

\begin{tabular}{|c|c|c|}
\hline Reaction & Conditions & Rate $(\mathrm{Kmol} / \mathrm{l} \mathrm{h})$ \\
\hline $\begin{array}{c}\text { Anisole Hydrogenation over } \\
\quad 0.5 \% \mathrm{Pd} / \mathrm{BEA}(58)\end{array}$ & $\begin{array}{c}\text { Temp }=155^{0} \mathrm{C} \text {; press }=25 \mathrm{H}_{2} \text { bar; } \\
400 \text { RPM }\end{array}$ & $1.4 \times 10^{-3}$ \\
\hline $\begin{array}{c}\text { Anisole Hydrogenation over } \\
0.5 \% \mathrm{Pd} / \mathrm{NaY}(5.1)\end{array}$ & $\begin{array}{c}\text { Temp }=155^{\circ} \mathrm{C} ; \text { press }=25 \mathrm{H}_{2} \text { bar; } \\
400 \mathrm{RPM}\end{array}$ & $7.9 \times 10^{-4}$ \\
\hline $\begin{array}{l}\text { Anisole Hydrogenation over } \\
\quad 0.5 \% \mathrm{Ru} / \mathrm{BEA}(58)\end{array}$ & $\begin{array}{c}\text { Temp }=155^{0} \mathrm{C} ; \text { press }=25 \mathrm{H}_{2} \text { bar; } \\
400 \mathrm{RPM}\end{array}$ & $1.3 \times 10^{-4}$ \\
\hline $\begin{array}{l}\text { Acetophenone hydrogenation } \\
\text { over } 0.5 \% \mathrm{Pd} / \mathrm{BEA}(58)\end{array}$ & $\begin{array}{c}\text { Temp }=155^{0} \mathrm{C} ; \text { press }=25 \mathrm{H}_{2} \text { bar; } \\
400 \mathrm{RPM}\end{array}$ & $8 \times 10^{-4}$ \\
\hline $\begin{array}{l}\text { Acetophenone hydrogenation } \\
\text { over } 0.5 \% \mathrm{Pd} / \mathrm{NaY}(5.1)()\end{array}$ & $\begin{array}{c}\text { Temp }=155^{0} \mathrm{C} ; \text { press }=25 \mathrm{H}_{2} \text { bar; } \\
400 \mathrm{RPM}\end{array}$ & $4 \times 10^{-4}$ \\
\hline Acetophenone hydrogenation & Temp $=155^{\circ} \mathrm{C}$; press $=25 \mathrm{H}_{2}$ bar; & $8 \times 10^{-5}$ \\
\hline
\end{tabular}




\begin{tabular}{|c|c|c|}
\hline over $0.5 \% \mathrm{Ru} / \mathrm{BEA}(58)$ & $400 \mathrm{RPM}$ & \\
\hline Anisole Hydrogenation over & $\begin{array}{c}\text { Temp }=90^{\circ} \mathrm{C} \text {; press }=20 \mathrm{H}_{2} \text { bar } \\
\text { and water: dichloromethane } \\
\text { solvent }\end{array}$ & \\
& $9.5 \times 10^{-5}$ \\
& 92.8 Cyclohexane converstion & \\
\hline Acetophenone hydrogenation & Temp=80 ${ }^{0} \mathrm{C}$; press $=40 \mathrm{H}_{2}$ bar \\
over 5\% Pd/C & and methanol solvent & \\
& 70 converstion & \\
\hline
\end{tabular}

